\title{
Mathematics in Utilizing Remote Sensing Data for Investigating and Modelling Environmental Problems
}

\author{
Hasi Bagan, ${ }^{1,2}$ Ram Avtar, ${ }^{3}$ Hajime Seya, ${ }^{4}$ and Huade Guan ${ }^{5}$ \\ ${ }^{1}$ Institute of Urban Studies, Shanghai Normal University, Shanghai 200234, China \\ ${ }^{2}$ Center for Global Environmental Research, National Institute for Environmental Studies, Tsukuba, Japan \\ ${ }^{3}$ United Nations University, Tokyo, Japan \\ ${ }^{4}$ Hiroshima University, Higashihiroshima, Japan \\ ${ }^{5}$ Flinders University, Adelaide, SA, Australia
}

Correspondence should be addressed to Hasi Bagan; hasi.bagan@nies.go.jp

Received 8 June 2017; Accepted 8 June 2017; Published 27 August 2017

Copyright (C) 2017 Hasi Bagan et al. This is an open access article distributed under the Creative Commons Attribution License, which permits unrestricted use, distribution, and reproduction in any medium, provided the original work is properly cited.

Remote sensing data have already proven useful for environmental monitoring in a timely, detailed, and cost-effective manner to assist various planning and management activities. Remotely sensed data collected over a span of years can be used to identify and characterize both natural and anthropogenic changes over large areas of land at a variety of spatial and temporal scales [1-3]. As climate change and population growth place increasing pressures on many parts of the world, improved methods for monitoring urban growth across a range of spatial and temporal scales will be vital for understanding and addressing the impacts of urbanization on our natural resources $[4,5]$. With the advance of machine learning algorithms and computing facilities, many investigations on their real applications are taking place. Combining remote sensing data and mathematics techniques to quantitatively analyze environmental change is a topic growing in importance [6]. The meaningful interpretation of remote sensing data and in situ observations require implementation and analysis using advanced mathematics and statistical techniques.

The objective of this special issue is to provide a snapshot of status, potentials, challenges, and achievements of mathematical application in using remote sensing data to address environmental issues. This special issue includes thirteen papers that cover four major topics: image processing methods, land use/land cover change analysis, land degradation, urbanization, and vegetation cover. A brief description of these 13 works is detailed below. (i) "Multisensor Fusion of Landsat Images for HighResolution Thermal Infrared Images Using Sparse Representations" by H. S. Jin and D. Han investigates a method of fusing Landsat panchromatic and thermal infrared images using a sparse representation (SR) technique. Their results show that the proposed method improves spatial resolution and preserves the thermal properties of basic LST data for use with environmental problems.

(ii) "A Subpixel Matching Method for Stereovision of Narrow Baseline Remotely Sensed Imagery" by N. Ma et al. proposes a subpixel image matching approach based on improved phase correlation through the analysis of narrow baseline remotely sensed imagery stereovision.

(iii) In order to assess the feasibility of the BeiDou Navigation Satellite System reflected signals (BeiDou-R) in detecting oil slicks, the paper by Y. Zhang et al. performs a BeiDou-R coastal simulation experiment on the oil slick distribution of an oil pipeline explosion accident. Their analysis reveals that oil slicks can be detected within a radius of less than $5 \mathrm{~km}$ around the specular reflection point for BeiDou-R coastal simulation.

(iv) With using grey relational analysis, "Analysis of the Spatial Variation of Soil Salinity and Its Causal Factors in China’s Minqin Oasis" by T. Qian et al. evaluates 
the factors that affect soil salinity and investigates the interactions among them in China's Minqin Oasis. The factors are ranked based on the significance of their impacts on soil salinity for different land use and cover types. They find that the main factors that affect soil salinity in the region's sparse grassland are groundwater salinity and vegetation cover.

(v) Population increase, excessive land development, overgrazing, and collection of fuel wood have been the main driving forces in Horqin's desertification process. "A Detailed and High-Resolution Land Use and Land Cover Change Analysis over the Past 16 Years in the Horqin Sandy Land, Inner Mongolia" by $\mathrm{X}$. Bai et al. presents a detailed and high-resolution $(30 \mathrm{~m})$ land cover change analysis over the past 16 years in Ongniud Banner, western part of the Horqin Sandy Land. The land cover classification was performed by combining multiple features calculated from the Landsat archive products using the Support Vector Machine (SVM) based supervised classification approach. This study implies increasing demand of water and indicates that the conservation of water resources is crucial for protecting the sensitive ecological zones in the Horqin Sandy Land.

(vi) "Analysis of Drought Characteristics in Xilingol Grassland of Northern China Based on SPEI and Its Impact on Vegetation" by S. Tong et al. explores the spatial and temporal dynamics of SPEI and NDVI over the Xilingol grassland and investigates the impact of drought on the NDVI in Xilingol grassland during the growing season.

(vii) The detection of decreasing vegetation cover is very important due to its impact on ecosystems. "Detection of Decreasing Vegetation Cover Based on Empirical Orthogonal Function and Temporal Unmixing Analysis" by D. Xu et al. applied a new method of integrated empirical orthogonal function (EOF) and temporal unmixing analysis (TUA) to detect the vegetation decreasing cover in Jiangsu Province of China.

(viii) Monitoring and mapping of urban growth and developing effective urban planning strategies require spatiotemporal extent and expansion trends of cities. The Beijing-Tianjin-Hebei Region (Jing-Jin-Ji) is a core source for China's rapid economic growth. "Dynamic Changes Analysis and Hotspots Detection of Land Use in the Central Core Functional Area of JingJin-Ji from 2000 to 2015 Based on Remote Sensing Data" by Y. Li et al. uses GIS spatial analysis and grid technologies to study the dynamic changes, hotspot regions, and driving forces in land use of the central core functional area of Jing-Jin-Ji. The results indicate that the level of land use was very uneven in the central core functional area of Jing-Jin-Ji.

(ix) "Dynamic Changes of Typical Blowouts Based on High-Resolution Data: A Case Study in Hulunbuir Sandy Land, China" by Y. Yang et al. studies the dynamic changes of typical blowouts within the past decade which were analyzed via multiperiod highresolution remote sensing images. RTK was used to repeatedly measure the blowouts to obtain their highprecision 3D terrain data in 2010, 2011, and 2012.

(x) The distribution of cities around the world broadly corresponds to the brightness distribution of DMSP nighttime lights. "Evaluating Urbanization and Spatial-Temporal Pattern Using the DMSP/OLS Nighttime Light Data: A Case Study in Zhejiang Province" by $\mathrm{P}$. Xu et al. using DMSP/OLS night-lighting data, mutation detection, regression analysis, and spatial analysis methods to analyze the urbanization in Zhejiang province, China.

(xi) The study of spatial planning for urban development is very important due to its impact on urban ecosystems. "Implications of a Spatial Multicriteria Decision Analysis for Urban Development in Ulaanbaatar, Mongolia" by P. Myagmartseren et al. illustrates how multicriteria decision analysis and geographical information systems can be used for more effective urban planning. This study shows the effect of using poor elevation data and how a sensitivity analysis can be applied to yield further information, spot weighting weaknesses, and assess the quality of the criteria.

(xii) "An Integrated Field and Hyperspectral Remote Sensing Method for the Estimation of Pigments Content of Stipa Purpurea in Shenzha, Tibet" by B. Kong et al. investigates the typical hyperspectral variables sensitive to chlorophyll content of Stipa purpurea and established the estimation model of chlorophyll.

(xiii) "Hierarchical Sea-Land Segmentation for Panchromatic Remote Sensing Imagery" by L. Ma et al. proposed a fully automatic sea-land segmentation approach for practical use with a hierarchical coarseto-fine procedure. They compared the proposed method with other state-of-the-art methods with real images under complex backgrounds and conducted quantitative comparisons. The experimental results show that proposed method outperforms all other methods and proved being computationally efficient.

We wish this special issue would inspire more ideas in utilizing mathematics and statistical techniques in the study of earth system (land, ocean, and atmosphere) environments.

\section{Acknowledgments}

We would like to take this opportunity to sincerely thank all of the authors and peer reviewers for their efforts devoted to this special section.

Hasi Bagan

Ram Avtar

Hajime Seya

Huade Guan 


\section{References}

[1] K. M. Bergen, T. Zhao, V. Kharuk et al., "Changing regimes: forested land cover dynamics in central Siberia 1974 to 2001," Photogrammetric Engineering and Remote Sensing, vol. 74, no. 6, pp. 787-798, 2008.

[2] C. Gómez, J. C. White, and M. A. Wulder, "Optical remotely sensed time series data for land cover classification: a review," ISPRS Journal of Photogrammetry and Remote Sensing, vol. 116, pp. 55-72, 2016.

[3] J. van Vliet, D. A. Eitelberg, and P. H. Verburg, "A global analysis of land take in cropland areas and production displacement from urbanization," Global Environmental Change, vol. 43, pp. 107-115, 2017.

[4] H. Bagan and Y. Yamagata, "Land-cover change analysis in 50 global cities by using a combination of Landsat data and analysis of grid cells," Environmental Research Letters, vol. 9, no. 6, Article ID 064015, 2014.

[5] C. Bren d'Amour, F. Reitsma, G. Baiocchi et al., "Future urban land expansion and implications for global croplands," Proceedings of the National Academy of Sciences, p. 201606036, 2016.

[6] D. J. Lary, A. H. Alavi, A. H. Gandomi, and A. L. Walker, "Machine learning in geosciences and remote sensing," Geoscience Frontiers, vol. 7, no. 1, pp. 3-10, 2016. 


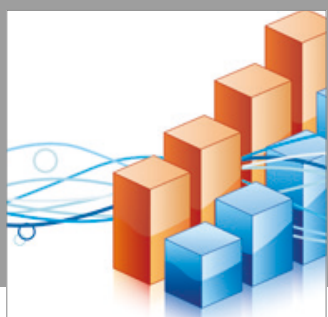

Advances in

Operations Research

vatersals

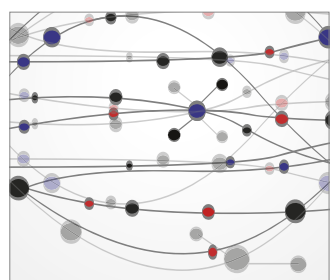

\section{The Scientific} World Journal
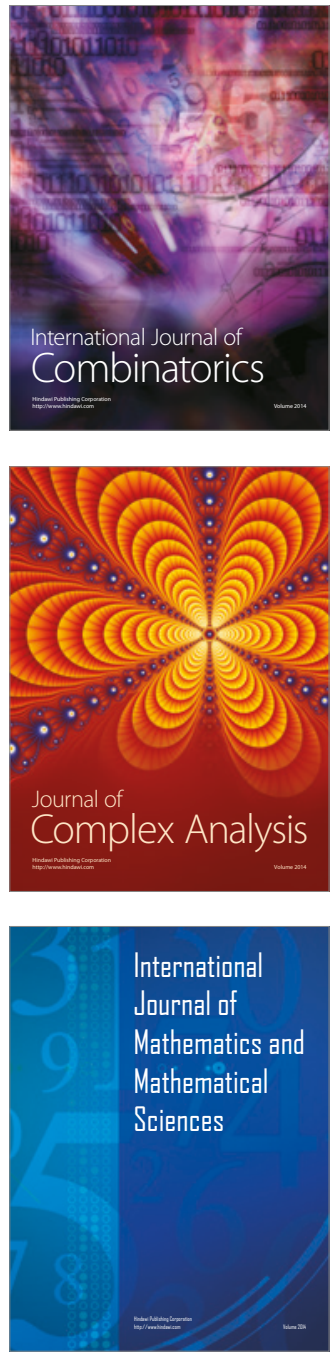
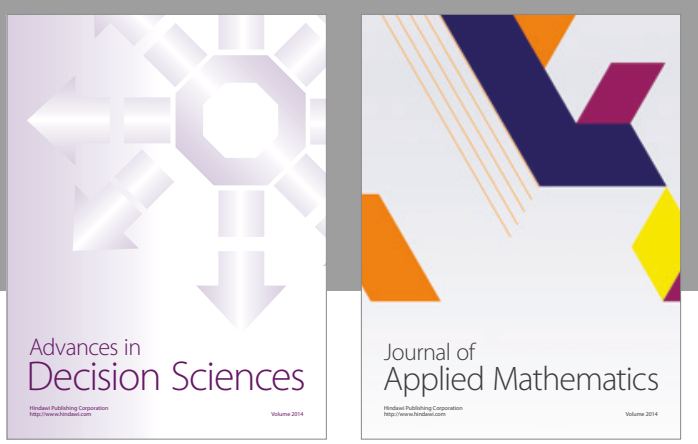

Algebra

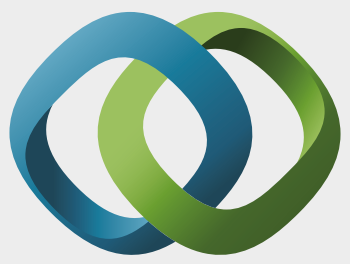

\section{Hindawi}

Submit your manuscripts at

https://www.hindawi.com
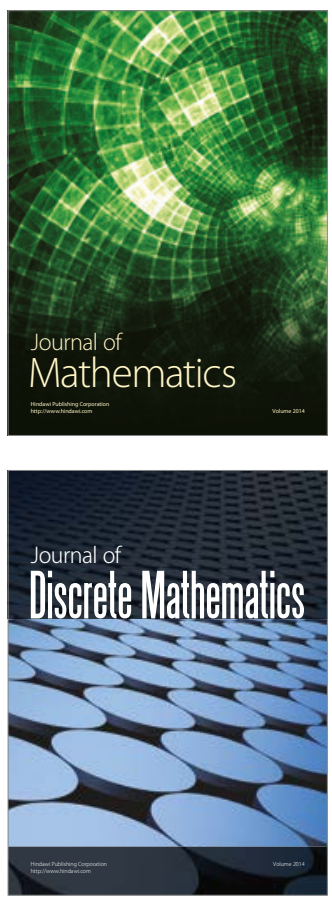

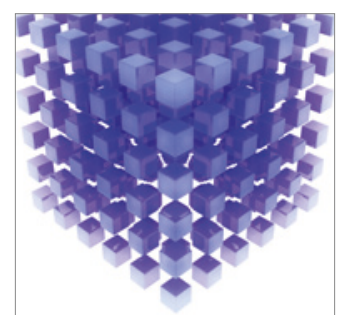

Mathematical Problems in Engineering
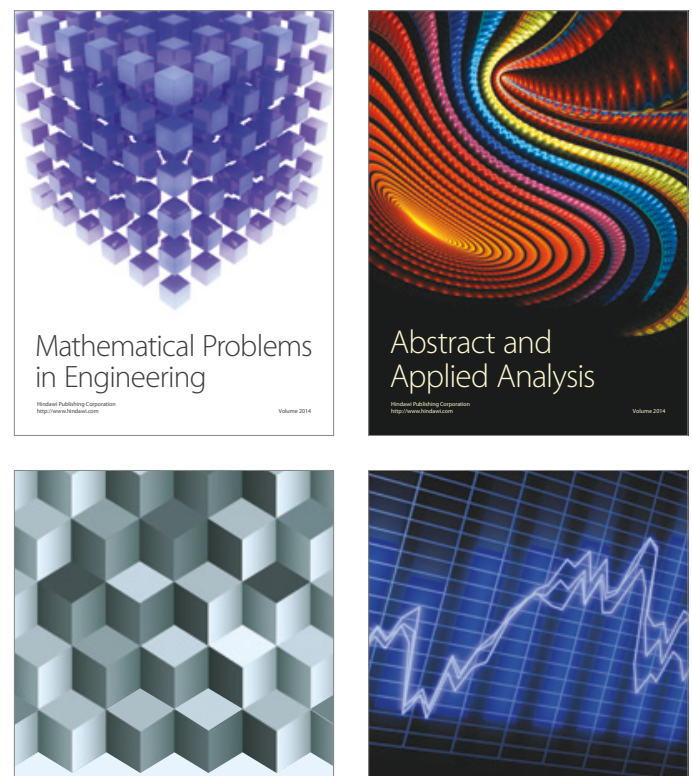

Journal of

Function Spaces

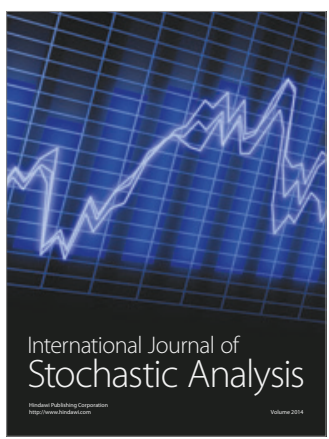

Probability and Statistics
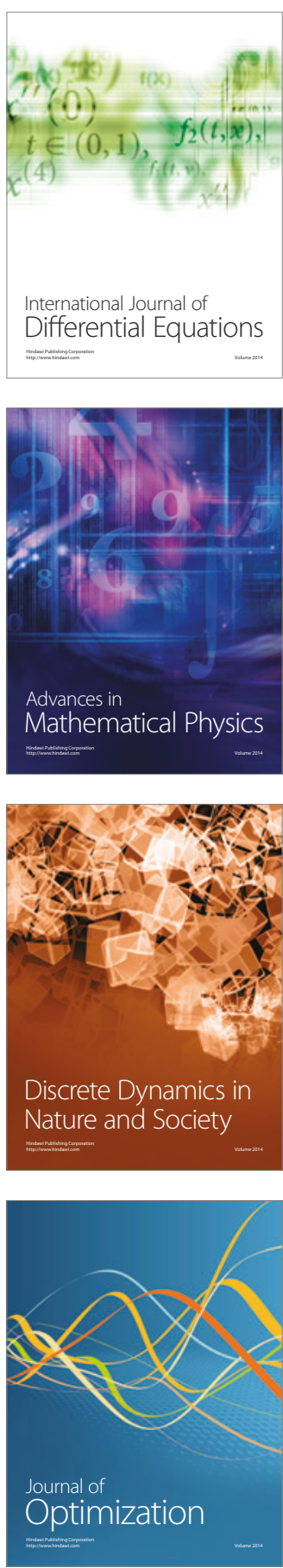